\title{
Preliminary Compositional Evidence of Provenance of Ceramics from Hatahara Archaeological Site, Central Amazonia
}

\author{
K. P. Nunes, ${ }^{1}$ R. G. Toyota, ${ }^{1}$ P. M. S. Oliveira, ${ }^{1}$ E. G. Neves, ${ }^{2}$ \\ E. A. A. Soares, ${ }^{3}$ and C. S. Munita ${ }^{1}$ \\ ${ }^{1}$ Instituto de Pesquisas Energéticas e Nucleares, IPEN-CNEN/SP USP, Avenida Prof. Lineu Prestes 2242, \\ Cidade Universitária, 05508-000 São Paulo, SP, Brazil \\ ${ }^{2}$ Museu de Arqueologia e Etnologia, Universidade de São Paulo (USP), Cidade Universitária, 05508-900 São Paulo, SP, Brazil \\ ${ }^{3}$ Departamento de Geociências, Universidade Federal do Amazonas, CEP 69007-000, Manaus, AM, Brazil
}

Correspondence should be addressed to C. S. Munita; camunita@yahoo.com

Received 31 May 2013; Accepted 2 September 2013

Academic Editor: Yiannis Kourkoutas

Copyright (C) 2013 K. P. Nunes et al. This is an open access article distributed under the Creative Commons Attribution License, which permits unrestricted use, distribution, and reproduction in any medium, provided the original work is properly cited.

\begin{abstract}
One hundred twenty four ceramic fragments and six clay samples from the Hatahara archaeological site in Amazonas state, Brazil, were analyzed using instrumental neutron activation analysis, INAA, to determine the concentration of twenty chemical elements: $\mathrm{Ce}, \mathrm{Co}, \mathrm{Cr}, \mathrm{Cs}, \mathrm{Eu}, \mathrm{Fe}, \mathrm{Hf}, \mathrm{K}, \mathrm{La}, \mathrm{Lu}, \mathrm{Na}, \mathrm{Nd}, \mathrm{Rb}, \mathrm{Sc}, \mathrm{Ta}, \mathrm{Tb}, \mathrm{Th}, \mathrm{U}, \mathrm{Yb}$, and Zn. The dataset was submitted to multivariate statistical analysis. The classification was done by cluster analysis and discriminant analysis. The results demonstrated the occurrence of four different groups of ceramics, which represent three archaeological phases: Paredão, Manacapuru, and Guarita. This data is consistent with previous traditional petrographic examination of the ceramic samples. Based on probability measures, the great majority of the ceramics are considered to be local in origin.
\end{abstract}

\section{Introduction}

Archaeological ceramics are the most abundant tracers in archaeological studies because they maintain their characteristics for many years, constitute a historic record, and can reflect the behavior patterns of ancient communities. For this reason, the chemical analysis of this kind of sample has attracted the attention of many authors worldwide [1].

The production technology, provenance and use of the ceramics by ancient communities have been the main issues approached since 1950 when the first studies of these materials began to appear [2]. The determination of provenance probably forms the primary role of geochemical analyses in archaeological ceramic studies.

In provenance studies, the elementary concentrations in ceramics and clays are chemically and mineralogically correlated. By determining the trace elements in both ceramics and clays, the raw material used for their manufacture can be identified. The group differentiation depends on the discriminant element concentration, which indicates whether there existed one or more clay deposits. Although it is a complex exercise, especially with purely chemical studies, there are cases in which this has been successful $[3,4]$. The main reason for this complexity is that the chemical and mineral compositions of ceramics do not correspond in a simple way to any one distinct raw material. A number of compositional changes may be introduced in the manipulation, and mixing of the raw material, as well as the history of the ceramic in use, the nature of the production process, and the postdepositional alteration can lead to compositional variations between the ceramic fabric and the raw material(s) used to produce it.

Due to these problems, it is common in ceramic provenance studies to compare archaeological pottery with reference material, comprised of ceramic samples with a known or assumed origin. Although successful in many cases, this approach relies on the opinion and assumptions of what comprises local pottery for a given archaeological site. Overall, raw materials used in ceramics continue to be the primary sources for interpreting the chemical and mineralogical diversity of pottery, in order to differentiate production units and determine their location. 
From this point of view, physical and chemical techniques are important tools for these kinds of studies. Among the various techniques, INAA employing $\gamma$-ray spectrometry seems to be most suitable analytical technique because it enables several elements to be simultaneously determined with high sensitivity, precision, and accuracy. Moreover, sample preparation is relatively easy and fast [5-7].

In this study, the concentration data for the elements $\mathrm{Ce}$, Co, Cr, Cs, Eu, Fe, Hf, K, La, Lu, Na, Nd, Rb, Sc, Ta, Tb, Th, $\mathrm{U}, \mathrm{Yb}$, and $\mathrm{Zn}$ was obtained via INAA on the ceramics and clay samples to determine the different production units and locations. In order to form chemical groups, the data was studied using cluster and discriminant analysis to find the source of the raw material used in the ceramics.

1.1. Study Area. The Hatahara site belongs to the district of Iranduba, $30 \mathrm{~km}$ southwest of Manaus, in the region located on the left margin of the Solimões river, next to where it merges with the Negro river [8]. The site demonstrates the history of four distinct phases of occupation: Paredão, Manacupuru, Guarita, and Açutuba [8]. The phases were established based on the decoration, form of the vessel, and mostly by the kind of the temper used in the paste. Such aspects characterize the site as complex in relation to its precolonial composition, and archaeometric studies are important in understanding the development of these communities.

The site is formed by a farm that encompasses $160,000 \mathrm{~m}^{2}$ in a fertile valley in the center of the Amazon. This region contains both dry and flooded land (swamp). The dry land, which is not inundated by the annual river's flooding, is sustained by sedimentary rocks formations Alter do Chão and Novo Remanso from the Cretaceous and Miocene periods, respectively [9-11]. The swamp area, inundated by annual floods, corresponds to the Quaternary sedimentary deposits from the Solimões and Ariaú river flood plains.

The site is characterized by an enormous extension along the Solimões river as well as by the presence of an enormous amount of ceramic material and black soil, which is a type of soil rich in organic material. This soil is present throughout the site's entire surface.

Artificially structured mounds were found at the site made from layers of oxisol, black organic soil, fauna, flora, and human burial remains [10].

\section{Experimental}

2.1. Sample Collection, Preparation, and Description of the Method. Care was taken during the collection of the samples to ensure, to the greatest extent possible, that duplicates from the same item of ceramic were not included in the sample set. The ceramics were tentatively identified as representing all archaeological phases.

Ceramic powder samples were obtained by cleaning the outer surface and drilling with a variable speed drill to a depth of $1-2 \mathrm{~cm}$, using a tungsten carbide rotary file attached to the end of a flexible shaft. Depending on the thickness, 3 or 5 holes were drilled as deep into the core of the fragment as possible without drilling through the walls. Clay samples were ground in an agate mortar until a granulometry of 100 mesh was achieved. Finally, the powered samples were dried in an oven at $105^{\circ} \mathrm{C}$ for $24 \mathrm{~h}$ and stored in desiccators [5, 7].

Constituent elements in Coal Fly Ash - NIST-SRM-1633b were used as the standard in every analysis. The standard reference material IAEA Soil 7 (Trace Elements in Soil) was used to check the analytical quality of the results. The standards were dried in an oven at $105^{\circ} \mathrm{C}$ for $2 \mathrm{~h}$ and stored in a desiccator to be later weighed.

The bulk samples were analyzed using instrumental neutron activation analysis, following the routine measurement procedure applied to ceramics and clays [5]. Approximately $100 \mathrm{mg}$ of ceramics samples, NIST-SRM-1633b and Soil 7, was weighed in polyethylene bags and wrapped in aluminum foil. Groups of 8 ceramics samples and two reference materials were packed in aluminum foil and irradiated in the research reactor pool, IEA-R1 m (IPEN/CNEN-SP), at a thermal neutron flux of about $5 \times 10^{12} \mathrm{~cm}^{-2} \mathrm{~s}^{-1}$ for $8 \mathrm{~h}$.

Two measurement series were carried out using Ge (hyperpure) detector, model GX 2519 from Canberra, with a resolution of $1.90 \mathrm{keV}$ at the $1332.49 \mathrm{keV}$ gamma peak of ${ }^{60} \mathrm{Co}$. Spectra were collected with a Canberra S-100 multichannel analyzer with 8192 channels. K, La, Lu, Na, Nd, Sm, U, and Yb were measured after 7 days of cooling time, and $\mathrm{Ce}, \mathrm{Co}, \mathrm{Cr}$, Cs, Eu, Fe, Hf, Rb, Sb, Sc, Ta, Tb, Th, and Zn were measured after 25-30 days. Gamma-ray spectra analysis was carried out using the Genie 2000 NAA Procedure software from Canberra [5].

\section{Results and Discussion}

The analytical quality control of the analysis was tested using 28 independent determinations of the reference material IAEA Soil-7. The results observed were compared to the certified values. Some statistical studies were applied to the dataset, such as mean, mean confidence interval, and relative standard deviation. The results showed that most elements had a precision of $\leq 10 \%$. This precision is considered by several authors as appropriate for the choice of chemical elements for provenance studies using multivariate statistical methods [12]. The clays in the different sampling loci of the region may not differ greatly in composition; therefore, the method of analysis must be sensitive enough to cope with this problem. Since the Co determination showed a precision of less than $10 \%$, it was eliminated in the dataset due to contamination by tungsten carbide during the sample preparation [13].

The determination of $\mathrm{Zn}$ is not reliable as a consequence of a strong $\gamma$-ray interference by ${ }^{46} \mathrm{Sc}$ and ${ }^{182} \mathrm{Ta}$. The interference by the ${ }^{235} \mathrm{U}$ fission in determining the $\mathrm{La}, \mathrm{Ce}$, and $\mathrm{Nd}$ was negligible because the $U$ concentration did not exceed 5 ppm and the rare earth elements were not extremely low [14]. $\mathrm{Nd}, \mathrm{Rb}$, and $\mathrm{Sb}$ showed a good precision; however, previous studies have shown that there are no reliable elements to include in the database due to the natural heterogeneity [15]. Therefore, the elements used in the subsequent studies were $\mathrm{Ce}, \mathrm{Cr}, \mathrm{Cs}, \mathrm{Eu}, \mathrm{Fe}, \mathrm{Hf}, \mathrm{K}, \mathrm{La}, \mathrm{Lu}, \mathrm{Na}, \mathrm{Sc}, \mathrm{Tb}, \mathrm{Th}, \mathrm{U}$, and $\mathrm{Yb}$. None of these elements contained missing values. The mean, standard deviation, minimum, and maximum are presented in Table 1. 
TABle 1: Mean, standard deviation, and range for the ceramic samples, $n=124$, and clay, $n=6$, in $\mu \mathrm{g} / \mathrm{g}$ unless otherwise indicated.

\begin{tabular}{|c|c|c|c|c|c|c|c|c|}
\hline Element & Mean \pm SD & Range & Clay 1 & Clay 2 & Clay 3 & Clay 4 & Clay 5 & Clay 6 \\
\hline $\mathrm{Na}, \%$ & $0.3 \pm 0.1$ & $0.1-0.7$ & 0.8 & 0.1 & 0.7 & 1.2 & 1.2 & 0.6 \\
\hline $\mathrm{K}, \%$ & $1.2 \pm 0.4$ & $0.4-2.6$ & 1.6 & 0.9 & 1.5 & 2.3 & 2.3 & 2.5 \\
\hline $\mathrm{La}$ & $38.9 \pm 7.9$ & 20.1-93.9 & 43.6 & 24.4 & 36.8 & 36.4 & 39.7 & 56.8 \\
\hline $\mathrm{Yb}$ & $2.8 \pm 0.6$ & $1.6-7.7$ & 4.1 & 3.3 & 2.8 & 3.3 & 3.1 & 3.6 \\
\hline $\mathrm{Lu}$ & $0.4 \pm 0.1$ & $0.3-1.2$ & 0.5 & 0.5 & 0.4 & 0.4 & 0.5 & 0.6 \\
\hline $\mathrm{U}$ & $3.2 \pm 0.7$ & $0.5-7.5$ & 3.6 & 3.9 & 3.3 & 3.2 & 3.2 & 3.5 \\
\hline $\mathrm{Ce}$ & $73.2 \pm 11.1$ & $39.5-96.8$ & 107.9 & 40.9 & 73.0 & 76.3 & 81.3 & 105.7 \\
\hline $\mathrm{Cr}$ & $61.7 \pm 8.2$ & $40.8-89.0$ & 60.1 & 91.5 & 59.1 & 60.6 & 63.0 & 92.7 \\
\hline Cs & $6.4 \pm 1.7$ & $2.6-10.6$ & 7.3 & 8.3 & 7.1 & 4.6 & 5.3 & 13.7 \\
\hline $\mathrm{Eu}$ & $1.2 \pm 0.2$ & $0.7-1.9$ & 1.7 & 0.5 & 1.3 & 1.5 & 1.7 & 1.8 \\
\hline $\mathrm{Fe}, \%$ & $3.3 \pm 0.7$ & $1.5-4.7$ & 4.0 & 6.3 & 3.0 & 4.1 & 4.4 & 3.9 \\
\hline $\mathrm{Hf}$ & $5.8 \pm 2.4$ & $3.1-17.6$ & 8.1 & 11.4 & 9.4 & 8.9 & 9.5 & 4.7 \\
\hline Sc & $14.5 \pm 1.9$ & $9.1-19.3$ & 14.7 & 14.6 & 13.6 & 14.8 & 15.6 & 21.4 \\
\hline $\mathrm{Tb}$ & $0.7 \pm 0.2$ & $0.3-1.4$ & 1.2 & 0.8 & 1.2 & 0.8 & 0.8 & 0.6 \\
\hline Th & $13.3 \pm 2.0$ & $8.7-20.0$ & 12.0 & 17.6 & 11.7 & 12.0 & 12.9 & 17.2 \\
\hline
\end{tabular}

In geochemistry, concentration data is often assumed to follow a lognormal distribution after being $\log _{10}$ transformed, as suggested by Ahrens [16]; however, in geochemistry, this assumption rarely holds true. For the majority of the variables, a log base 10 transformation does not result in a normal distribution [17]. This fact may have serious consequences to the later statistical treatment of datasets because the vast majority of advanced statistical methods require not only that each variable shows a normal distribution but also that the variables show a multivariate normal distribution. In addition, although the dataset does not present the total composition of the samples, that is, the variables measured are $<100 \%$, this type of data frequently displays a curvature. In this paper, the transformation proposed by Aitchison [18] was used, so each sample $x_{i j}(i=1, \ldots, n$ and $j=1, \ldots, p)$ was transformed into $y_{i j}$ by taking the natural log transformation and subtracting the mean of the transformed variables; that is,

$$
y_{i j}=\ln x_{i j}, \quad \bar{y}_{i}=\frac{1}{p} \sum_{j=1}^{p} y_{i j} \quad z_{i j}=y_{i j}-\bar{y}_{i} .
$$

In addition, the data was standardized to offset the large differences in magnitude between the elements measured at trace levels and the more prevalent elements [19]. The most universally used method is $z$-transformation, in which the raw data is subtracted by the mean and then divided by the standard deviation of the data. When working with geochemical data, a robustified version, using the median and the median absolute deviation (MAD) is preferred instead of the mean and standard deviation [20]. Therefore, this procedure was used as follows [19]:

$$
z \text {-transformation }=\frac{z_{i j}-\operatorname{median}\left(z_{i}\right)}{\operatorname{MAD}\left(z_{i}\right)} .
$$

In turn, the dataset was submitted to outlying tests using the Mahalanobis distance. Outliers can have a considerable influence on multivariate statistical methods because they can disturb homogeneous groups.

The Mahalanobis distance is an important measure in statistics and has been suggested by many authors as the best method for detecting outliers in multivariate data. For each of the $n$ samples and $p$ variables, the Mahalanobis distance $\left(D_{i}\right)$ was taken from the sample to the centroid, as calculated by the expression [20]

$$
D_{i}=\sqrt{\left(x_{i}-\bar{x}\right)^{\prime} S^{-1}\left(x_{i}-\bar{x}\right)}
$$

where ${ }^{\prime}$ is the transpose matrix, $S=\sum_{i=1}^{n}\left(x_{i}-\bar{x}\right)^{\prime}\left(x_{i}-\bar{x}\right)$ is the variance-covariance sampling matrix, and $\left(x_{i}-\bar{x}\right)$ is the vector of difference between the concentrations measured in one group and the concentrations measured in the other group. Each one of these values is compared with the critical value, cv, which can be calculated using the lambda Wilks criteria [21], calculated as follows:

$$
\frac{p(n-1)^{2} F_{p, n-p-1 ; \alpha / n}}{n\left(n-p-1+p F_{p, n-p-1, \alpha / n}\right)},
$$

where $p$ is the number of variables, $n$ is the number of samples and $F$ is the $F$ test called "Fisher distribution" $\left(F=s_{1}^{2} / s_{2}^{2}\right.$ where $s_{1}^{2}$ and $s_{2}^{2}$ are the sample variances), with $p$ degrees of freedom at a significance level of $\alpha / n, \alpha=0.05$.

When the value found by expression (3) is larger than the critical value produced by expression (4), the sample is considered to be an outlier [22]. Thus, the Mahalanobis distance values for each sample were calculated and compared to the critical value. In accordance with the Mahalanobis distance rule, three ceramics sample outliers were found and removed from the data. Due to the small size of this compositional group, it is difficult to know whether it is a real group. We believe that the outlier samples could be related to contamination processes that may have occurred during burial, and this notion is strengthened by the fact that 


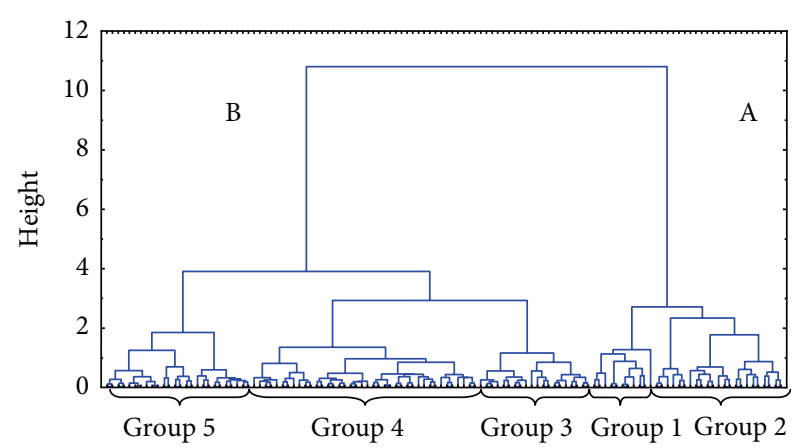

Group
1: Manacapuru
2: Paredão, Manacapuru, and Guarita
3: Manacapuru
4: Paredão and others
5: Paredão, Manacapuru, and Guarita

FIGURE 1: Dendrogram of the ceramics sample using squared Euclidean distance and Ward's method, $n=121$.

lower or higher concentrations of $\mathrm{Fe}, \mathrm{Cr}, \mathrm{K}, \mathrm{U}, \mathrm{Tb}, \mathrm{Th}$, $\mathrm{La}$, and $\mathrm{Ce}$ were found compared to other samples. This result is not altogether surprising because correlations exist between elements that are geochemically related and that are neighbors or nearly neighbors in the same group, subgroups, or series in the periodic table. For example, members of the lanthanide series ( $\mathrm{La}, \mathrm{Ce}$ ) demonstrate strong positive correlations, as do members of the actinide series (U and Th) and the elements of the first transition series (Fe and Co).

Cluster analysis is routinely applied to analytical data with the purpose of identifying groups of chemically similar shards, which can be interpreted as representing vessels made from the same raw materials or mixtures of raw materials and therefore presumably made in the same place although not necessarily at the same time.

The data from the remaining 121 ceramics samples were submitted to cluster analysis on a $121 \times 15$ matrix, in which the columns represented the analyzed elements and the rows the samples using Ward's method and square Euclidean distance. Ward's method was employed because it tends to form groups with high internal homogeneity and takes account of the cluster structure. In all statistical studies, the software used was $\mathrm{R}$ version 2.4.1.

In Figure 1, the dendrogram shows that the samples were classified into five primary groups, linked at different levels of similarity. With such a large number of samples, the identifiers normally displayed along the bottom of the diagram became unreadable and had to be omitted. A clear distinction exists between the two branches of the dendrogram, A and B, which indicates a high level of dissimilarity. With the purpose of studying the relationship between these two groups without any influence from the other half, the data was split into two, along the lines indicated in Figure 1. Each half was then clustered independently. The dendrogram obtained, but not presented here, showed clusters with the

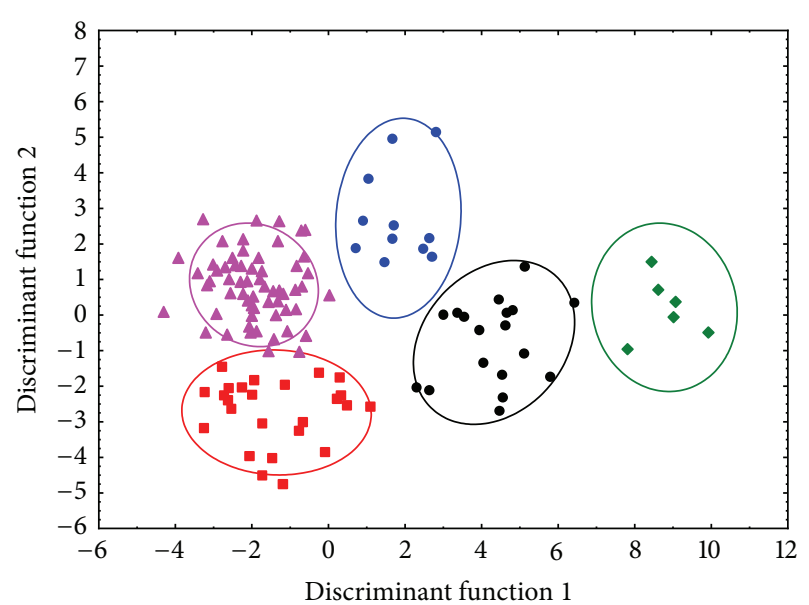

- Manacapuru
- Paredão, Manacapuru, and Guarita
- Manacapuru
- Paredão and others
- Paredão, Manacapuru, and Guarita

FIGURE 2: Discriminant function 1 versus discriminant function 2 for the ceramic samples, $n=121$. The ellipses represent $95 \%$ confidence level for sample inclusion in the cluster.

same samples from group A or B. During the statistical evaluation, it became clear that sample A showed a significantly different composition. For the samples of group A, the major elements that contributed to the separation were Hf $(14.7 \%)$, Fe (13.4\%), and Th (11.6), and for samples B, they were Th (10\%), Ce (10.1\%), and La (10.7\%).

As can be seen in Figure 1, the samples were separated into five groups that were very similar in chemical composition among the samples of each group. This fact allowed for five distinct sources of raw materials that were used in ceramics production at the Hatahara site. In accordance with the archaeological context, the site has distinct ceramics phases which involved the direct observation, and study of variability in ceramic production, distribution and use [23]. ${ }^{14} \mathrm{C}$ dating studies have shown that the ceramic chronological phases fall between the years $300 \mathrm{BC}$ and $1500 \mathrm{AC}$. The phases of occupation were related to Manacapuru, from Tradição Borda Incisa, dated from $550 \mathrm{AC}$ to $650 \mathrm{AC}$. The Paredão phase, from 750 AC to $1020 \mathrm{AC}$, was associated to the construction of the artificial mounds. The occupation of the Paredão phase stands out from other occupations due to the construction of circular villages, mounds of artificial ceramics structures, black soil, and primary and secondary burials. The most superficial occupation is associated with the Guarita polychrome Amazon tradition, dated somewhere between $800 \mathrm{AC}$ and 1500 AC [23].

Following the cluster analysis, the data underwent discriminant analysis. Discriminant analysis was applied to the dataset with the objective of confirming the groups. Figure 2 shows the space defined by discriminant function 1 versus discriminant function 2 which explained $98 \%$ of the variance. The figure shows the five groups, with the samples 


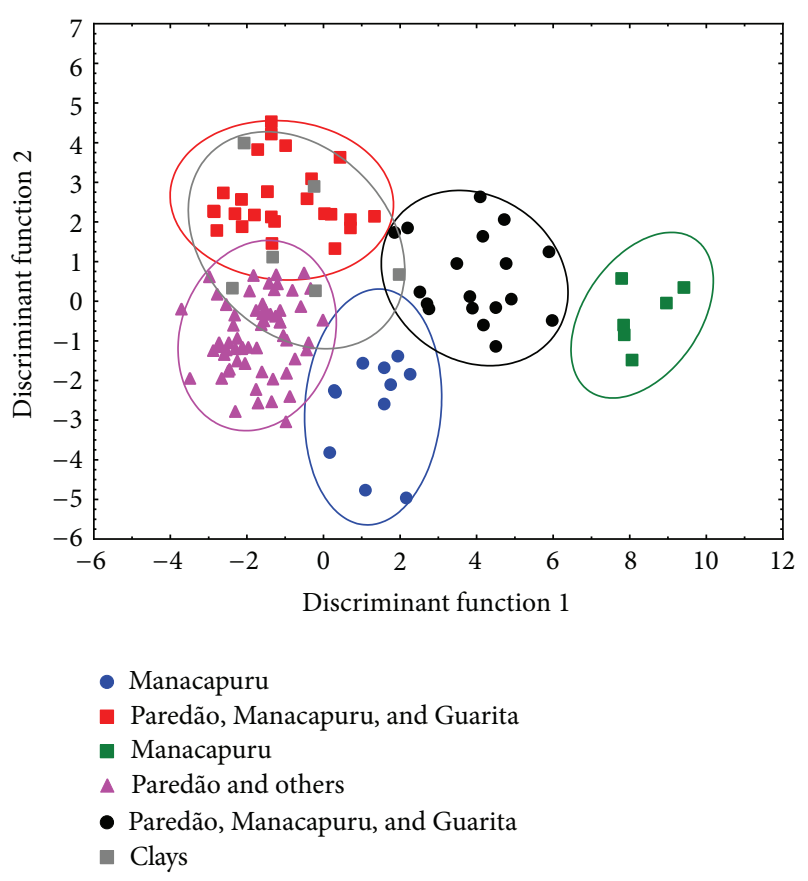

FIGURE 3: Discriminant function 1 versus discriminant function 2 for the ceramic $(n=121)$ and clays samples $(n=6)$. The ellipses represent $95 \%$ confidence level for sample inclusion in the cluster.

belonging to each group. It is possible to see that no variation occurred in relation to the number of groups formed by the dendrogram. Groups 1 and 3 are represented by ceramics belonging to the Manacapuru phase. These groups revealed only the presence of ceramics related to this phase, but they used a different source of clay for each group.

It is possible to also see that larger amounts of ceramics exist in Groups 2, 4, and 5 where the presence of the Paredão phase ceramics is predominant. Although in these groups the concentrations of some elements were similar, the concentrations among the groups varied greatly. The differences are clear in the alkali metals and the rare earth elements, particularly Eu (Table 1). The high Na concentration may be accounted for by the plagioclase content, and Eu may exist in the divalent state $\left(\mathrm{Eu}^{2+}\right)$ and it substitutes Sr in Ca plagioclase [24].

The clay samples were analyzed with the purpose of studying the raw material sources used in the production of the ceramic artifacts. The geographical domain of the provenience studies for the clays collected was confined to a relatively small region. In order to accomplish this, six clay samples were collected and analyzed by INAA. Three of them were collected fromthe Solimões river flood plains in front of the city of Iranduba, which is $6 \mathrm{~km}$ from the site. The other three clay samples were taken from the lowlands of the Ariaú river. The results are presented in Table 1 . The elementary concentrations of the clays were submitted to discriminant analysis together with ceramic samples in order to verify the distribution of the samples in the ceramics groups. Figure 3 shows discriminant function 1 versus discriminant function 2 for the clay and ceramics samples. The six clays show patterns that probably have a chemical composition that is somewhat similar to the ceramics of the Paredão phase and other undefined ceramic groups (clusters 2, 4, and 5). Considering the abundance of criteria, this suggests that probably clay could be used as raw material for the Paredão ceramic phase.

\section{Conclusion}

Through the analysis of $\mathrm{Ce}, \mathrm{Cr}, \mathrm{Cs}, \mathrm{Eu}, \mathrm{Fe}, \mathrm{Hf}, \mathrm{K}, \mathrm{La}, \mathrm{Lu}, \mathrm{Na}$, $\mathrm{Sc}, \mathrm{Tb}, \mathrm{Th}, \mathrm{U}$, and $\mathrm{Yb}$ in 121 ceramics samples and 6 clays from the Hatahara archaeological site determined through the INAA, it was possible to confirm the three different and concurrent phases of occupation as well as the probable source of the raw material used in the production of the ceramic artifacts. The results suggest that no single clay source was used at this site to manufacture the ceramics analyzed in this study. However, our conclusions are based on a small sample size, and further studies with the analysis of more clay samples are needed to confirm the provenance.

\section{Acknowledgment}

The authors wish to thank Fundação de Amparo à Pesquisa do Estado de São Paulo (FAPESP), Contracts 06/57343-3 and 08/54867-7, for financial support.

\section{References}

[1] M. S. Tite, "Ceramic production, provenance and use-a review," Archaeometry, vol. 50, no. 2, pp. 216-231, 2008.

[2] D. P. S. Peacock, "Scientific analysis of ancient ceramicsreview," World Archaeology, vol. 1, pp. 375-389, 1970.

[3] C. Knappett, D. Pirrie, M. R. Power, I. Nikolakopoulou, J. Hilditch, and G. K. Rollinson, "Mineralogical analysis and provenancing of ancient ceramics using automated SEM-EDS analysis (QEMSCAN@): a pilot study on LB I pottery from Akrotiri, Thera," Journal of Archaeological Science, vol. 38, no. 2, pp. 219-232, 2011.

[4] A. A. Usman, R. J. Speakman, and M. D. Glascock, "An initial assessment of prehistoric ceramic production and exchange in northern Yoruba, North Central Nigeria: results of ceramic compositional analysis," African Archaeological Review, vol. 22, no. 3, pp. 141-168, 2005.

[5] R. Hazenfratz, G. Mongeló, C. S. Munita, and E. G. Neves, "Comparison of INAA elemental composition data between Lago Grande and Osvaldo archaeological sites in the central Amazon: a first perspective," Journal of Radioanalytical and Nuclear Chemistry, vol. 291, no. 1, pp. 43-48, 2012.

[6] J. O. Santos, C. S. Munita, R. G. Toyota, C. Vergne, R. S. Silva, and P. M. S. Oliveira, "The archaeometry study of the chemical and mineral composition of pottery from Brazil's Northeast," Journal of Radioanalytical and Nuclear Chemistry, vol. 281, no. 2, pp. 189-192, 2009.

[7] C. S. Munita, R. P. Paiva, M. A. Alves, P. M. S. De Oliveira, and E. F. Momose, "Contribution of neutron activation analysis to archaeological studies," Journal of Trace and Microprobe Techniques, vol. 18, no. 3, pp. 381-387, 2000.

[8] J. S. Machado, Montículos artificiais na Amazônia central: um estudo de caso do sítio Hatahara [M.S. thesis], Museu de 
Arqueologia e Etnologia, Universidade de São Paulo, Brazil, 2005.

[9] E. A. A. Soares, C. L. Silva, A. C. R. Nogueira, K. Suguio, D. S. Barros, and W. H. D. Santos, Os depósitos quaternários na confluência dos rios Negro e Solimões, municípios de Iranduba e Manacapuru, Amazonas, VII Simpósio de Geologia da Amazônia, Belém, Sociedade Brasileira de Geologia, Núcleo Norte, 2001.

[10] E. A. A. Soares, Pleistocene deposits of the region of confluence of Negro and Solimões rivers, Amazonas [Ph.D. thesis], Instituto de Geociências, Universidade de São Paulo, Brazil, 2007.

[11] E. A. A. Soares, S. H. Tatumi, and C. Riccomini, "OSL age determinations of Pleistocene fluvial deposits in Central Amazonia," Anais da Academia Brasileira de Ciencias, vol. 82, no. 3, pp. 691699, 2010.

[12] R. L. Bishop, V. Canouts, P. L. Crown, and S. P. De Atley, "Sensitivity, precision and accuracy: their roles in ceramic compositional data bases," American Antiquity, vol. 55, no. 3, pp. 537546, 1990.

[13] M. Attas, J. M. Fossey, and L. Yaffe, "Corrections for drill-bit contamination in sampling ancient pottery for neutron activation analysis," Archaeometry, vol. 26, pp. 104-107, 1984.

[14] M. D. Glascock, "Characterization of ceramics at MURR by INAA and multivariate statistics," in Chemical Characterization of Ceramic Paste in Archaeology, Monographs in World Archaeology, H. Neff, Ed., pp. 11-26, Prehistory Press, New York, NY, USA, 1992.

[15] C. S. Munita, A. Nascimento, S. B. Schreiber, S. Luna, and P. M. S. Oliveira, "Chemical study of some ceramics from Brazilian Northeast," Journal of Radioanalytical and Nuclear Chemistry, vol. 259, no. 2, pp. 305-309, 2004.

[16] L. H. Ahrens, "The lognormal distribution of the elements," Geochimica et Cosmochimica Acta, vol. 5, no. 2, pp. 49-73, 1954.

[17] C. Reimann and P. Filzmoser, "Normal and lognormal data distribution in geochemistry: death of a myth. Consequences for the statistical treatment of geochemical and environmental data," Environmental Geology, vol. 39, no. 9, pp. 1001-1014, 2000.

[18] J. Aitchison, "Principal component analysis of compositional data," Biometrika, vol. 70, no. 1, pp. 57-65, 1983.

[19] M. Templ, P. Filzmoser, and C. Reimann, "Cluster analysis applied to regional geochemical data: problems and possibilities," Applied Geochemistry, vol. 23, no. 8, pp. 2198-2213, 2008.

[20] F. E. Grubbs, "Sample criteria for testing outlying observations," Annual of Mathematical Statistics, vol. 21, pp. 27-58, 1950.

[21] K. I. Penny, "Appropriate critical values when testing for a single multivariate outlier by using the mahalanobis distance," Journal of the Royal Statistical Society C, vol. 45, no. 1, pp. 73-81, 1996.

[22] P. M. S. Oliveira, C. S. Munita, and R. Hazenfratz, "Comparative study between three methods of outlying detection on experimental results," Journal of Radioanalytical and Nuclear Chemistry, vol. 283, no. 2, pp. 433-437, 2010.

[23] L. Rebellato, Interpreting the pottery variability and the chemical and physical signatures of the soil in the Hatahara archaeological site, AM [M.S. thesis], Museu de Arqueologia e Etnologia, Universidade de São Paulo, Brazil, 2007.

[24] S. M. McLennan, "Rare-earth elements in sedimentaryrocks-influence of provenance and sedimentary processes," Reviews in Mineralogy, vol. 21, pp. 169-200, 1989. 

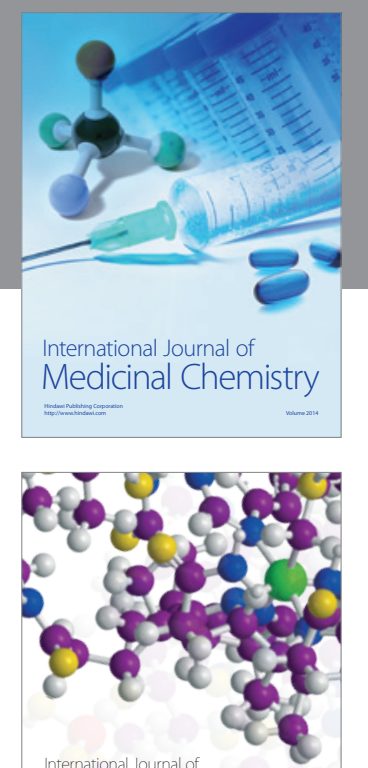

\section{Carbohydrate} Chemistry

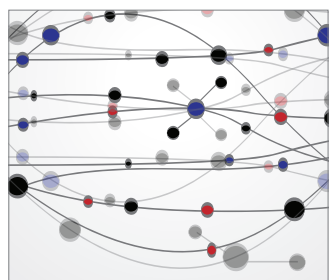

The Scientific World Journal
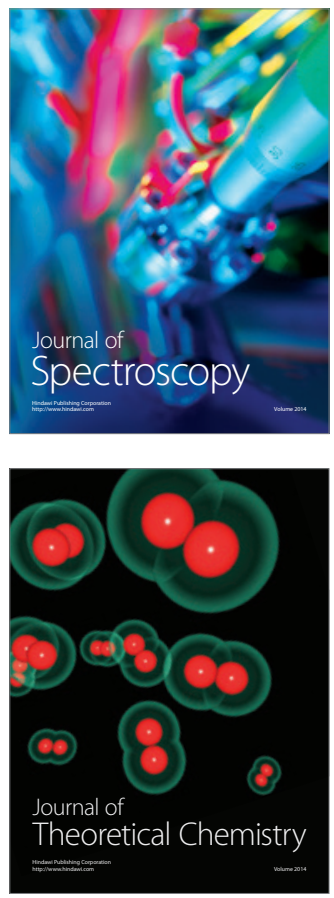
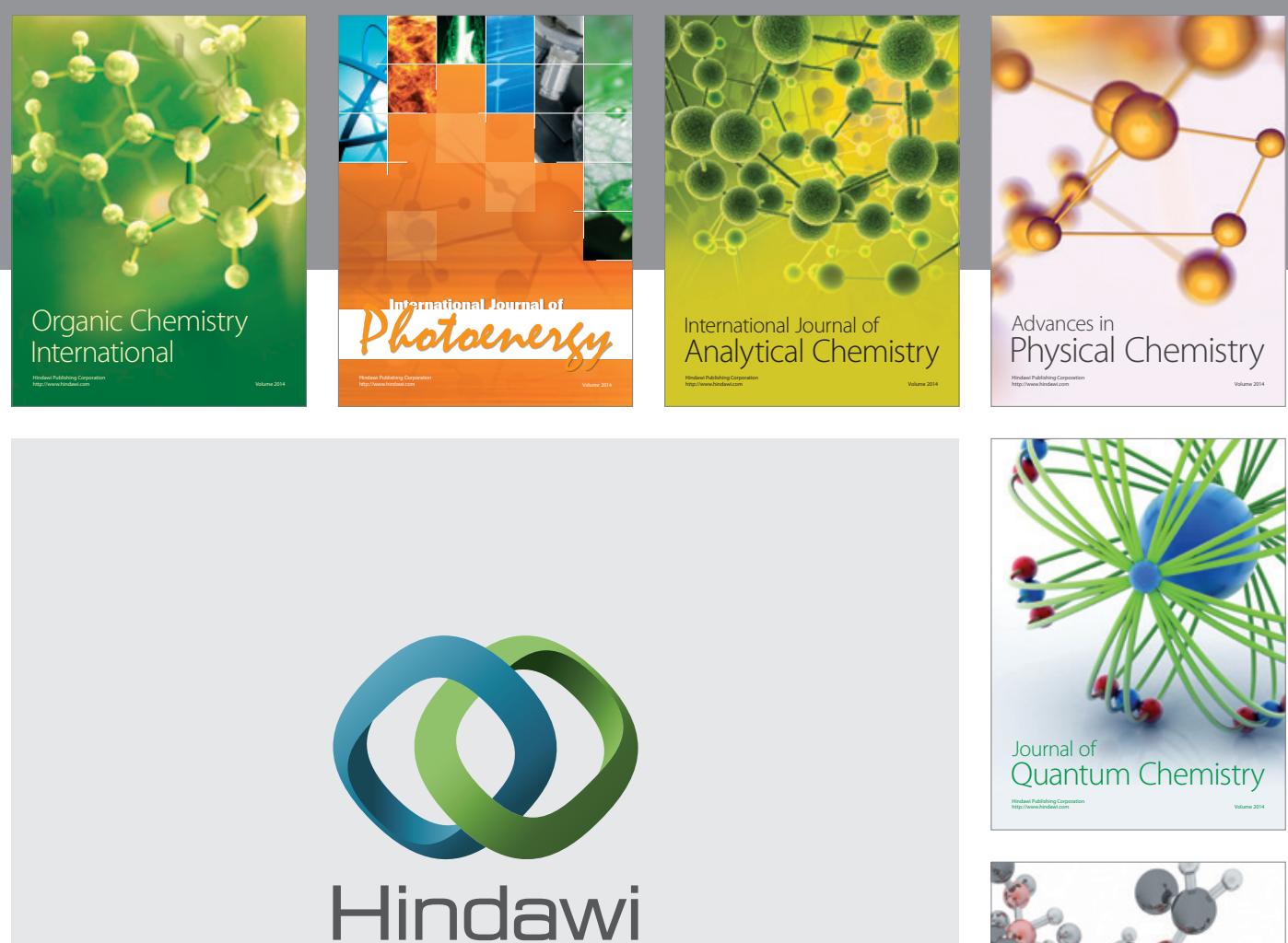

Submit your manuscripts at

http://www.hindawi.com

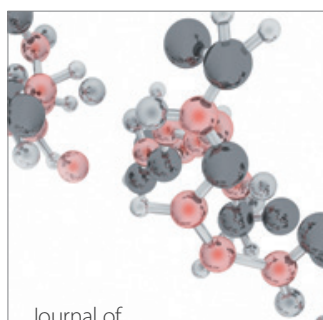

Analytical Methods

in Chemistry

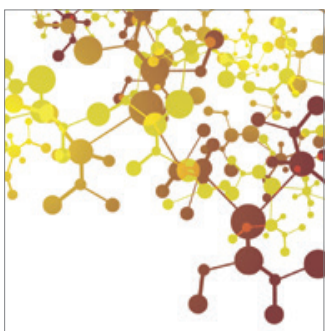

Journal of

Applied Chemistry

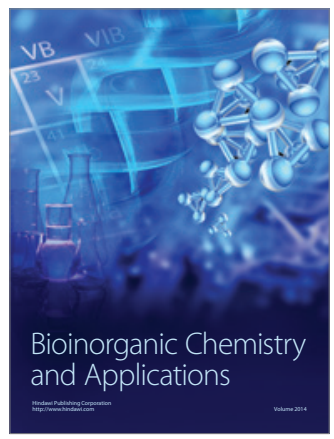

Inorganic Chemistry
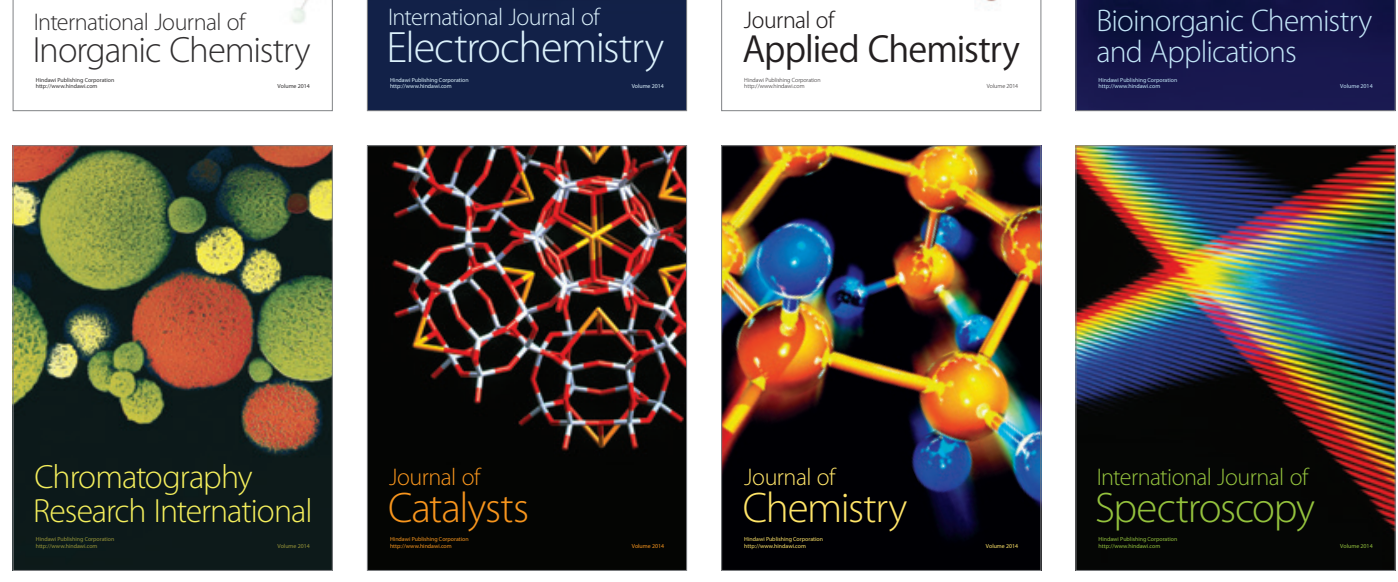